\title{
Efeito da Aloe arborescens Miller e da Aloe barbadensis Miller sobre o desenvolvimento vegetativo em Aspergillus nidulans
}

BERTI, A.P. ${ }^{*}$; PACHECO, L.S. ${ }^{2}$; ROCHA, C.L.M.S.C. ${ }^{2}$

1Universidade Estadual de Mato Grosso do Sul, Cidade Universitária de Dourados, Caixa Postal 351, CEP 79804-970, Dourados-MS, Brasil; 2Universidade Estadual de Maringá, Avenida Colombo, 5790, CEP 87020-900, Maringá-PR, Brasil, *Autor para correspondência:alessandrabiologa@hotmail.com

RESUMO: A pesquisa de produtos naturais benéficos à saúde humana vem crescendo nos últimos 20 anos. Considerando que as plantas de Aloe são amplamente utilizadas pela população humana, em geral de maneira terapêutica, o objetivo deste estudo foi avaliar os efeitos de Aloe arborescens Miller e Aloe barbadensis Miller, sobre o desenvolvimento vegetativo de linhagens normais e mutantes de Aspergillus nidulans. Conídios da linhagem biA1methG1, MSE e CLB3 de $A$. nidulans, foram inoculados em meio completo sem (Controle) e com extratos das duas espécies incubados por $2,4,6$ e 8 horas a $37^{\circ} \mathrm{C}$, no escuro. Foi analisado em microscópio óptico, 200 conídios de cada tratamento. Para o desenvolvimento das colônias, as linhagens foram inoculadas no centro das placas juntamente com o meio de cultura sólido e sobre a membrana de diálise, visando a medição do diâmetro e do peso. A análise estatística foi baseada no teste de Tukey e todos os procedimentos experimentais foram conduzidos em triplicata. Todas as linhagens apresentaram interferências positivas quando expostas às plantas de Aloe, porém, de maneira variada. Ambas as espécies aceleraram a germinação em todas as linhagens testadas e atuaram na redução significativa de conídios mortos e/ou malformados. Em relação ao desenvolvimento vegetativo, todos os dados referentes ao peso úmido e diâmetro corrigido dos tratamentos demonstraram progressos, contudo, a razão diâmetro/peso apresentou somente na linhagem MSE, ação favorável dos tratamentos naturais. As informações deste estudo sugerem benefícios de $A$. arborescens e $A$. barbadensis, justificando a importância e continuidade da investigação, para melhor elucidar os mecanismos de ação dessas plantas.

Palavras-chave: Plantas medicinais, Babosa, Germinação, Crescimento vegetativo.

ABSTRACT: Effects of the Aloe arborescens Millerand Aloe barbadensis Milleron over vegetative growth in the Aspergillus nidulans. The researches about natural products that arebeneficial to human health have been growing over the past 20 years. Since Aloe plants are broadly used by the general population, frequently due to therapeutic reasons, the objective of this study was to evaluate the effects of Aloe arborescens Millerand Aloe barbadensis Miller on the vegetative growth of normal and mutant strains of Aspergillus nidulans. The conidia of the biA1meth G1, MSE and CLB3 strains of $A$. nidulans were inoculated in complete environment without (control) and with extracts of two species of Aloeincubated for 2, 4, 6 and 8 hours at $37^{\circ} \mathrm{C}$. 200 conidia were analyzed by optical microscopy. For the development of the colonies, the strains were inoculated in the center of the plates together with the solid environment of the cultivation and over the dialysis membrane for measuring the diameter and weighing. The statistical analysis was based on the Tukey test and all experimental procedures were performed in triplicate. All strains showed positive interference when exposed to Aloe plants, however, through different manners. Both species have accelerated the germination in all tested strains and acted in the significant reduction of dead and / or malformed conidia. Regarding the vegetative growth, all data related to wet weight and corrected diameter of the treatments revealed progress, however, the ratio diameter/weightpresented improvement only in the MSE lineage, favorable action of natural treatments. The information from this study suggest that $A$. arborescens and $A$. barbadensis are beneficial, thus justifying the importance of research maintenance in order to better elucidate the action mechanisms of these plants.

Keywords: Medicinal plants, Aloe, Germination, Vegetative growth, Antioxidants. 


\section{INTRODUÇÃO}

O Brasil é mundialmente conhecido pela sua biodiversidade e, este fato aliado ao grande número de doenças provenientes do estilo de vida atual do homem, constitui um crescente interesse na descoberta de compostos naturais benéficos à saúde humana (Ferguson et al., 2004). Diante disso, na última década, uma nova área científica denominada Nutrigenômica, vem ganhando destaque, objetivando entender como os componentes da dieta afetam a expressão dos genes, bem como quais genes são induzidos e quais são reprimidos frente a um determinado nutriente (Sanhueza \& Valenzuela, 2012). Essa conjuntura de saúde, dieta e genômica promove um aumento no conhecimento de como a nutrição influencia o metabolismo e o controle homeostático do organismo (Afman \& Müller, 2006).

Grande parte da população humana dos países em desenvolvimento ainda depende da medicina tradicional, visto que $80 \%$ desta população utilizam práticas tradicionais nos seus cuidados básicos de saúde e $85 \%$ destes utilizam plantas ou preparações destas (OMS, 2003). Além disso, é evidente a importância de pesquisas com plantas medicinais para o uso de seus constituintes como agentes terapêuticos e matérias-primas para a produção de compostos farmacologicamente ativos (WHO, 2002).

Nesse contexto, as espécies Aloe arborescens Miller e Aloe barbadensis Miller se destacam devido o alto consumo pela população em geral e em função do seu grande valor medicinal. Porém, há milhares de anos, plantas do gênero Aloe têm suas virtudes registradas por diversas civilizações antigas, incluindo Grécia, Egito, África e Índia (Singh et al., 2000).

Pertencentes à Asphodelaceae (Wichtl, 2004) A. arborescens e A. barbadensis atuam beneficiando e protegendo o organismo por diferentes vias, por possuírem inúmeras propriedades, confirmadas pela comunidade científica, como imunoestimuladora (Lissoni et al., 2009), antioxidante (Ojha et al., 2001; Abo-youssef \& Messiha, 2013), antitumoral (Tomasin \& GomesMarcondes, 2011) e antidiabética/hipoglicemiante (Rajasekaran et al., 2004; Misawa et al., 2008; Aboyoussef \& Messiha, 2013).

Em virtude de possuir um sistema genético convencional bem caracterizado, o fungo Aspergillus nidulans, é empregado em pesquisas genéticas, sendo amplamente utilizado em estudos baseados em mutações e regulação genética, visto que seu crescimento é rápido, além de ser um organismo eucarioto (Baracho \& Baracho, 2003; Sousa et al., 2009). Ainda, experimentos com fungos reduzem a utilização indiscriminada de animais com fins experimentais em atividades de investigação.

Dessa forma, o presente estudo objetivou avaliar os efeitos de $A$. arborescens e $A$. barbadensis, sobre o desenvolvimento vegetativo de linhagens normais e mutantes de $A$. nidulans, visando descobrir os seus benefícios na homeostase de um organismo eucarioto.

\section{MATERIAL E MÉTODO Linhagens}

Foram utilizadas as linhagens normais de Aspergillus nidulans para o desenvolvimento vegetativo biA1methG1 e MSE, originadas de Glasgow (Escócia) e a linhagem CLB3, mutante para crescimento, esporulação e ciclo sexual, obtida no Laboratório de Genética Molecular e do Desenvolvimento, por mutação da linhagem biA1methG1.

\section{Tratamentos}

As plantas A. arborescens e A. barbadensis, pertencentes à Asphodelaceae, popularmente chamadas de Babosa, foram coletadas no Horto de Plantas Medicinais Profa Irenice Silva, da Universidade Estadual de Maringá, na cidade de Maringá, Paraná. As coletas foram realizadas no período de fevereiro a outubro de 2012, sendo utilizadas imediatamente para os experimentos. $A$. arborescens descrita por Mônica C. Sakuragui, com exsicata depositada no Herbário da Universidade Estadual de Maringá (HUEM 8603), A. barbadensis, descrita por José Badini, com exsicata no Herbário Prof. José Badini, da Universidade Federal de Ouro Preto (OUPR 13687).

As plantas A. arborescens e A. barbadensis foram preparadas a partir da remoção da casca e extração do gel (parênquima) de folhas frescas. Os géis foram processados em liquidificador e previamente filtrados em papel, posteriormente em filtro Millipore, com $20 \mu \mathrm{m}$ de poro. Ainda, foram diluídos em água para obtenção das doses estipuladas e usados para os tratamentos imediatamente, não sendo armazenados.

Foram empregadas duas concentrações de cada espécie: $A$. arborescens e $A$. barbadensis, sendo $4 \%(\mathrm{w} / \mathrm{v})$ e $8 \%(\mathrm{w} / \mathrm{v})$, resultando nos grupos: Água destilada (Controle), A. arborescens a 4\% (A4); A. arborescens a 8\% (A8); A. barbadensis a $4 \%$ (B4) e $A$. barbadensis a $8 \%(B 8)$.

\section{Meios de cultura}

Os meios de cultura utilizados foram meio completo líquido e sólido, preparados segundo Pontecorvo et al. (1953), Clutterbuck (1974) e Rocha (1997). 


\section{Variáveis analisadas}

\section{Germinação}

Conídios das três linhagens biA1meth 1 , MSE e CLB3 foram coletados de colônias com 5 dias de crescimento em meio completo, a $37^{\circ} \mathrm{C}$ e transferidos para $0,01 \%(\mathrm{v} / \mathrm{v})$ de Tween 80 . As suspensões de conídios foram filtradas em lã de vidro e inoculadas em meio completo com água destilada, referente ao controle (C) e com os tratamentos com ambas as espécies de Aloe a 4\% $(w / v)$ e $8 \%$ (w/v). Em seguida, foram transferidos para lâminas de microscopia em câmara úmida e incubadas por $2,4,6$ e 8 horas a $37^{\circ} \mathrm{C}$. Após cada um destes tempos, lâminas do controle e dos tratamentos foram observadas ao microscópio óptico. Foram analisados 200 conídios em cada lâmina, calculando-se a porcentagem de conídios em cada uma das fases: dormente, embebido, botão, germinado e malformado. Na última leitura, foi feita uma estimativa de sobrevivência, considerandose vivos apenas os conídios germinados. Todo o procedimento experimental foi realizado em triplicata.

\section{Crescimento da colônia}

Foram coletados conídios dormentes de cada uma das três linhagens de colônias com 5 dias e inoculados no centro de placas de petri contendo meio sólido (meio completo). Os tratamentos foram adicionados neste meio completo. A verificação do diâmetro das colônias foi realizada diariamente. Com estes elementos, foi estimada a velocidade de crescimento vegetativo da colônia. Todos os experimentos foram realizados em triplicata.
Relação entre diâmetro e peso da colônia

De cada linhagem, foram coletados de colônias de 5 dias, conídios dormentes e inoculados no centro de placas de petri contendo uma membrana de diálise sobre o meio sólido, em que já estavam os respectivos tratamentos. Após incubação a $37^{\circ} \mathrm{C}$, foram medidos diariamente, durante 10 dias o diâmetro de cada colônia e após este período, as mesmas foram pesadas em balança analítica. Com estes resultados, foi estimada a relação diâmetro/ peso média de cada linhagem em cada condição (Controle, A4, A8, B4, B8). Todo o procedimento experimental foi empregado em triplicata.

Foi calculado um diâmetro corrigido, a partir do peso úmido de cada linhagem, em cada tratamento, multiplicado pelo valor da razão diâmetro/peso da linhagem controle biA1meth 1 em meio completo, com intuito de comparar a massa micelial, além do que está demonstrado pelo peso úmido das colônias.

\section{Análise estatística}

A análise estatística foi feita pelo teste de Tukey $(p<0,001)$, no Programa Instat. As médias de todos os valores dos grupos tratamentos e controles foram comparados entre si, de cada variável analisada, de acordo com as respectivas linhagens. Todos os experimentos foram realizados em triplicata.

\section{RESULTADOS}

Em cada linhagem, as mucilagens apresentaram aceleração na velocidade de germinação em momentos diferentes. A linhagem biA1meth 1 demonstrou resultados estatisticamente

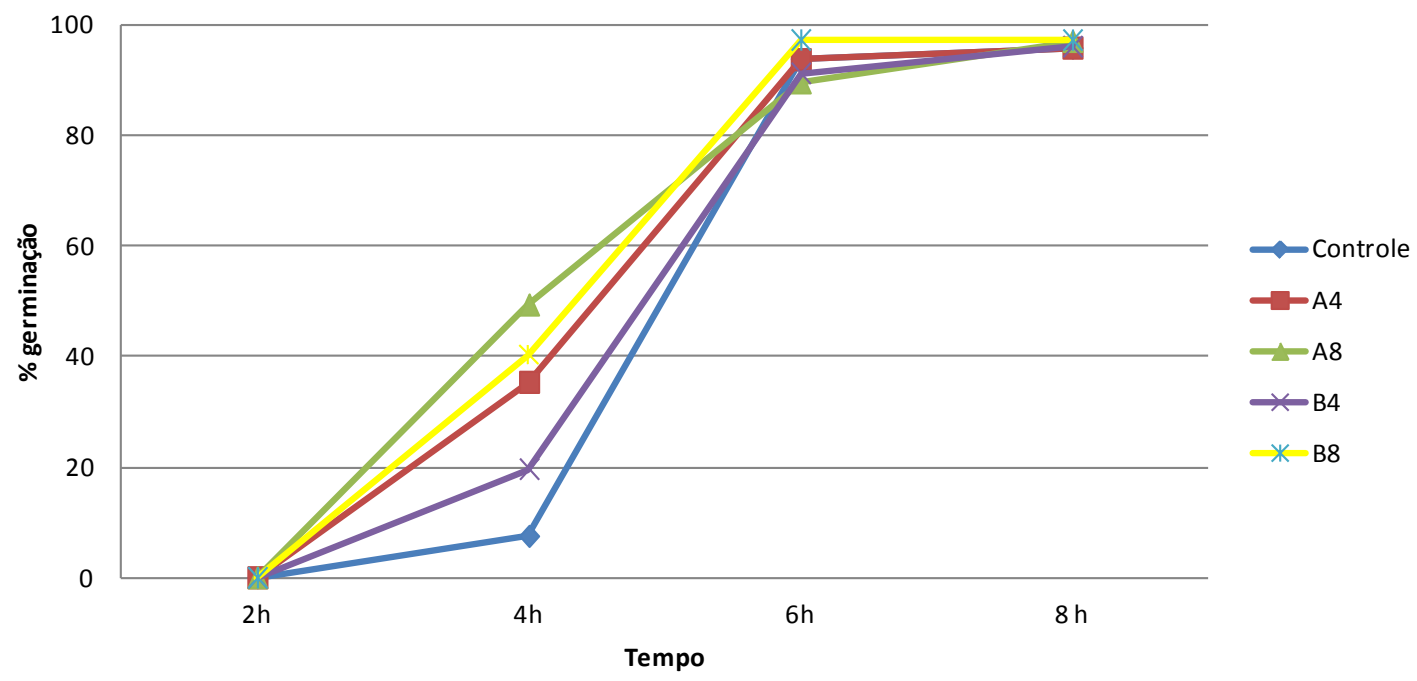

FIGURA 1. Porcentagem de germinação, tempo em horas, dos conídios sem tratamento (Controle) e com tratamento: A. arborescens 4\% (A4); A. arborescens 8\% (A8); A. barbadensis 4\% (B4) e A. barbadensis 8\% (B8), na linhagem biA1methG1. 


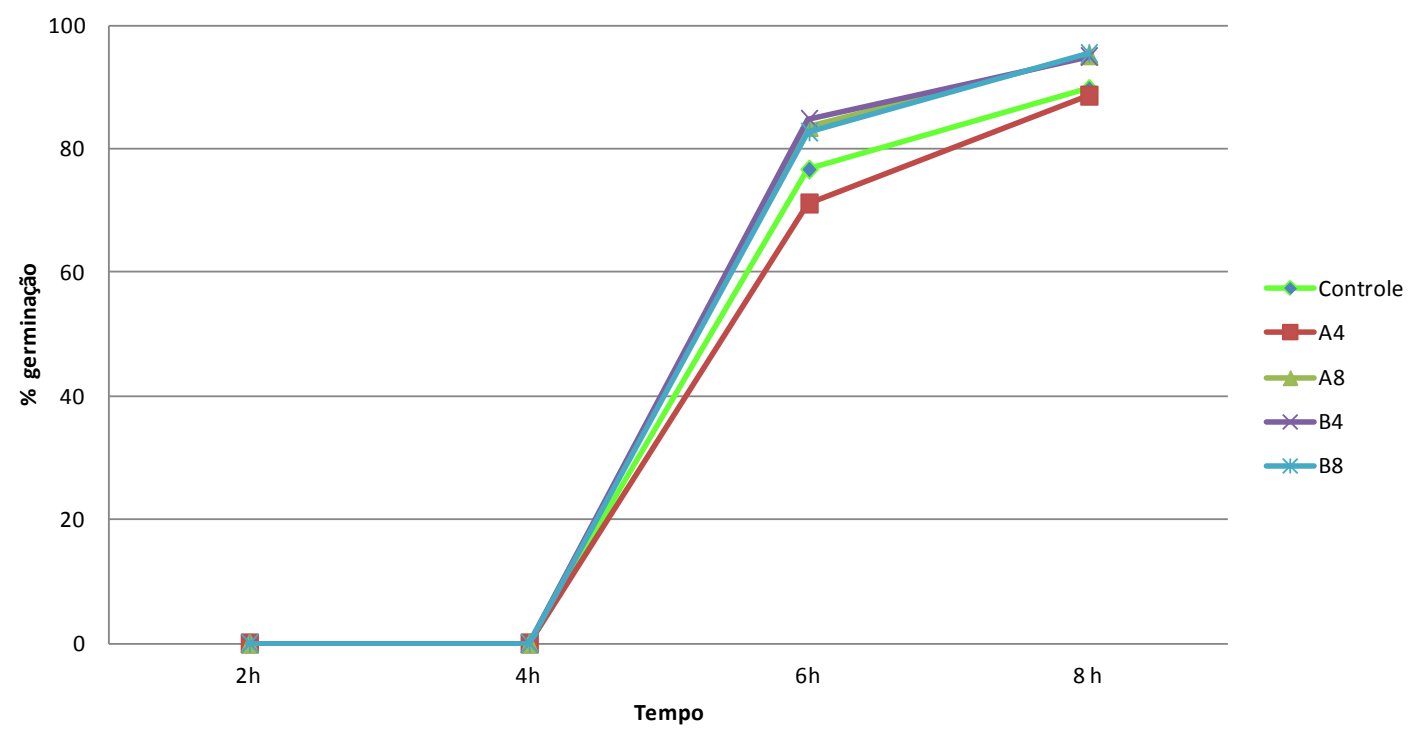

FIGURA 2. Porcentagem de germinação, tempo em horas, dos conídios sem tratamento (Controle) e com tratamento: A. arborescens 4\% (A4); A. arborescens 8\% (A8); A. barbadensis 4\% (B4) e A. barbadensis $8 \%$ (B8), na linhagem MSE.

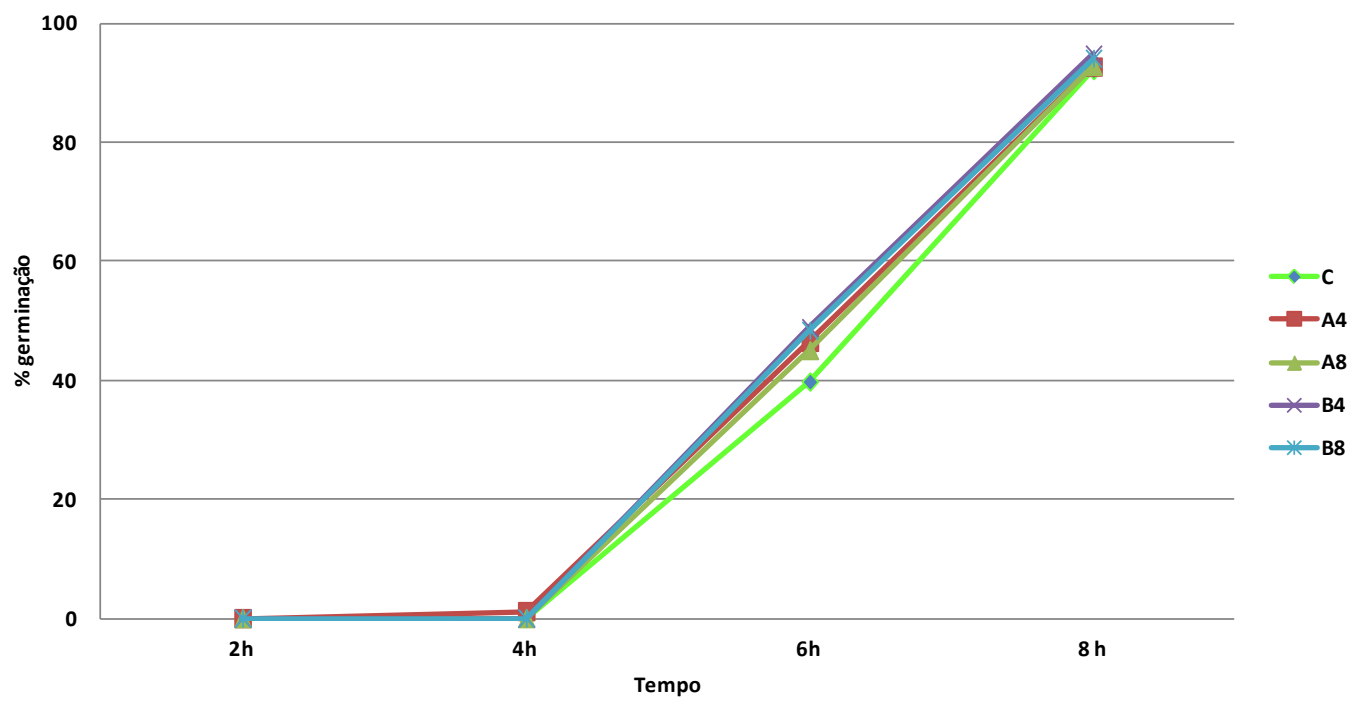

FIGURA 3. Porcentagem de germinação, tempo em horas, dos conídios sem tratamento (Controle) e com tratamento: A. arborescens 4\% (A4); A. arborescens 8\% (A8); A. barbadensis 4\% (B4) e A. barbadensis $8 \%$ (B8), na linhagem CLB3.

significativos dos grupos tratados em relação ao controle, na leitura de 4 horas (Figura 1). $\mathrm{Na}$ linhagem MSE, somente na leitura de 8 horas, os grupos A8 e B8 divergiram estatisticamente do controle (Figura 2), enquanto na linhagem CLB3, na leitura de 6 horas, todos os grupos tratados com os géis dos vegetais foram diferentes do controle, e todos os grupos se equipararam na leitura de 8 horas (Figura 3).

A Figura 4 mostra que os números de conídios mortos da linhagem biA1methG1 não apresentaram diferenças significativas em nenhum tratamento. Entretanto, as médias de malformados dos grupos A8, B4 e B8 foram diferentes, estatisticamente do Controle.

$\mathrm{Na}$ linhagem MSE, os grupos A8, B4 e B8 demonstraram redução expressiva de conídios mortos quando comparados ao Controle, enquanto o tratamento A4 aumentou a taxa dos mesmos. Já de acordo com as informações de malformados, apenas os grupos A8 e B4 foram significativamente diferentes tanto do controle como de A4, visto que apresentaram menor número de malformados (Figura 5).

Em relação à linhagem CLB3, todos os grupos expostos aos tratamentos com as plantas, diminuíram significativamente os conídios malformados. Perante as taxas de esporos mortos, 


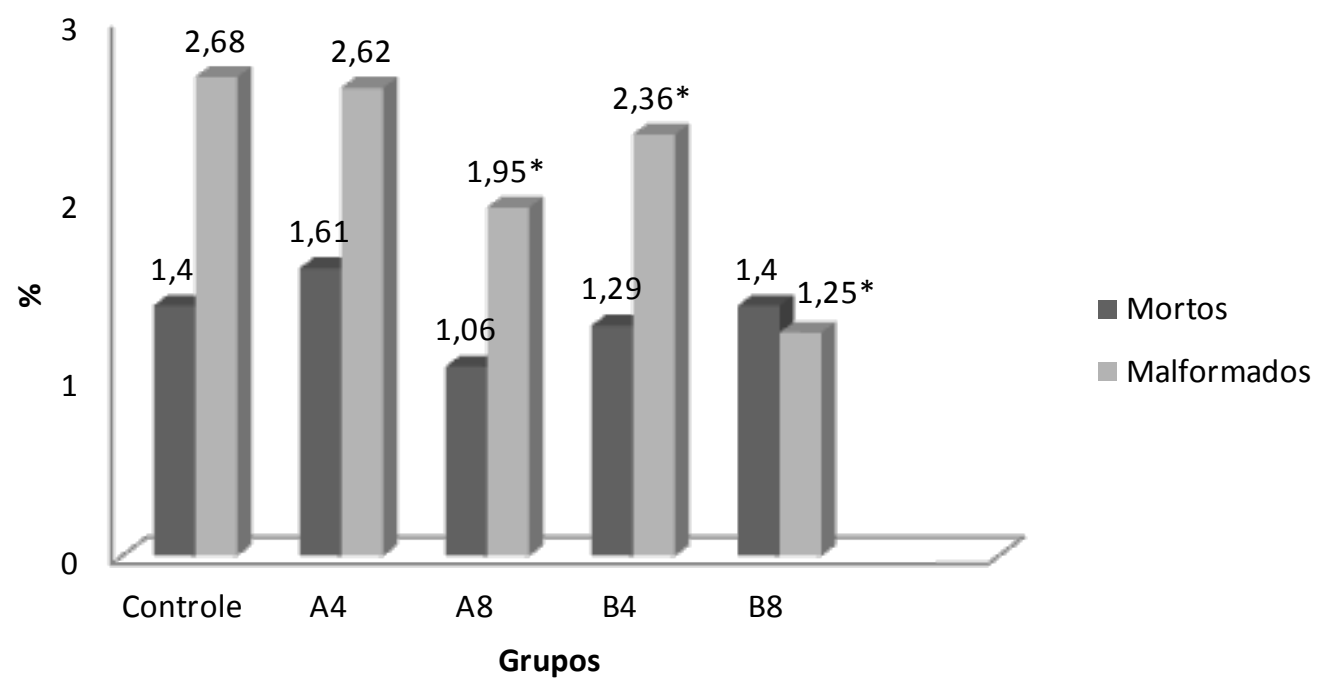

FIGURA 4. Percentual da média de conídios Mortos e Malformados, da linhagem biA1methG1, observados na leitura de 8 hs, dos grupos sem tratamento (controle) e com tratamento: $A$. arborescens 4\% (A4); $A$. arborescens 8\% (A8); A. barbadensis 4\% (B4) e A. barbadensis 8\% (B8). * Significativamente diferentes do Controle.

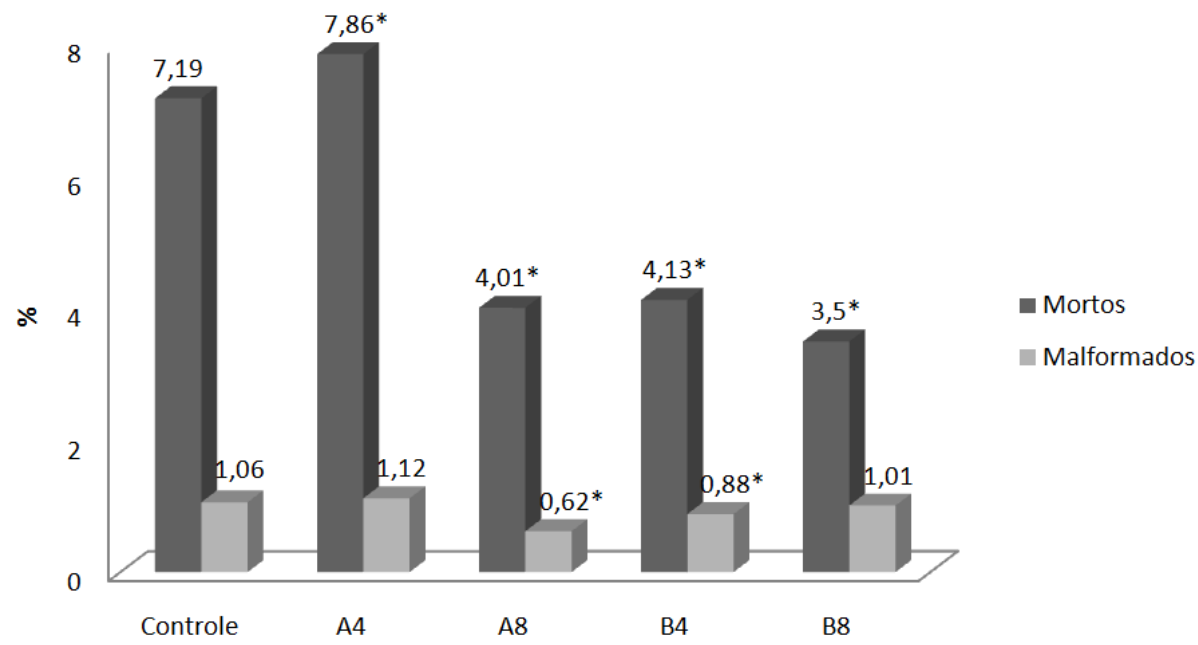

FIGURA 5. Percentual da média de conídios Mortos e Malformados, da linhagem MSE, observados na leitura de 8 hs, dos grupos sem tratamento (controle) e com tratamento: $A$. arborescens 4\% (A4); $A$. arborescens $8 \%$ (A8); A. barbadensis 4\% (B4) e A. barbadensis 8\% (B8). * Significativamente diferentes do Controle.

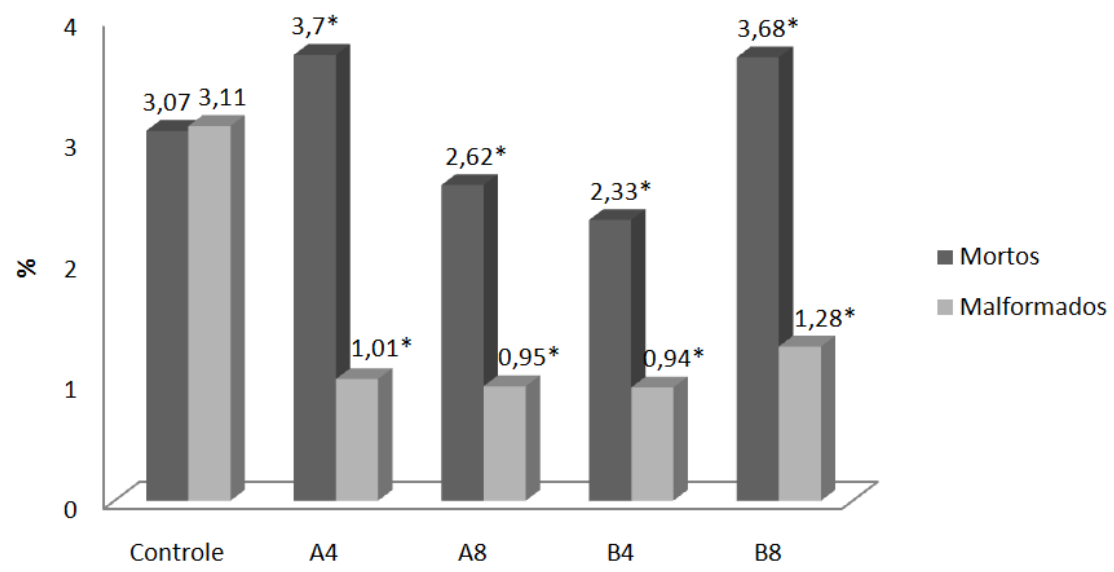

FIGURA 6. Percentual da média de conídios Mortos e Malformados, da linhagem CLB3, observados na leitura de 8 hs, dos grupos sem tratamento (controle) e com tratamento: $A$. arborescens $4 \%$ (A4); $A$. arborescens $8 \%$ (A8); A. barbadensis 4\% (B4) e A. barbadensis 8\% (B8). * Significativamente diferentes do Controle. 
TABELA 1. Variáveis analisadas das colônias das linhagens biA1methG1, MSE e CLB3 de $A$. nidulans com 10 dias de crescimento em meio completo sólido a $37{ }^{\circ} \mathrm{C}$, sem tratamento (Controle) e com tratamento: $A$. arborescens 4\% (A4); A. arborescens 8\% (A8); A. barbadensis 4\% (B4) e A. barbadensis 8\% (B8).

\begin{tabular}{|c|c|c|c|c|c|}
\hline Linhagens & Tratamento & $\begin{array}{l}\text { Peso úmido } \\
\text { (g) }\end{array}$ & $\begin{array}{l}\text { Diâmetro da colônia } \\
\qquad(\mathrm{cm})\end{array}$ & $\begin{array}{c}\text { Diâmetro/peso } \\
\text { (g) }\end{array}$ & $\begin{array}{l}\text { Diâmetro corrigido } \\
\text { (cm) }\end{array}$ \\
\hline \multirow{5}{*}{ biA1methG1 } & Controle & 0,846 & 8,430 & 9,950 & 8,43 \\
\hline & A4 & $0,883^{\circ}$ & 8,466 & $9,580^{*}$ & $8,80^{*}$ \\
\hline & A8 & $0,915^{*}$ & 8,250 & $9,010^{*}$ & $9,11^{*}$ \\
\hline & B4 & $0,922^{*}$ & 8,183 & $8,870^{*}$ & $9,18^{*}$ \\
\hline & B8 & $1,024^{\circ}$ & 8,333 & $8,130^{*}$ & $10,20^{*}$ \\
\hline \multirow{5}{*}{ MSE } & Controle & 1,017 & 8,333 & 8,190 & 10,13 \\
\hline & A4 & $1,099^{\circ}$ & 7,816 & $7,110^{*}$ & $10,95^{*}$ \\
\hline & A8 & $1,088^{\circ}$ & 8,016 & $7,360^{\circ}$ & $10,84^{\circ}$ \\
\hline & B4 & $1,088^{\circ}$ & 8,166 & $7,50^{\circ}$ & $10,84^{\circ}$ \\
\hline & B8 & $1,037^{\circ}$ & 8,000 & $7,710^{\circ}$ & $10,34^{\circ}$ \\
\hline \multirow{5}{*}{ CLB3 } & Controle & 1,065 & 4,833 & 4,530 & 10,61 \\
\hline & A4 & 1,125 & 4,866 & $4,320^{\circ}$ & $11,21^{\circ}$ \\
\hline & A8 & $1,133^{\circ}$ & 4,800 & $4,230^{\circ}$ & $11,28^{\circ}$ \\
\hline & B4 & $1,127^{\circ}$ & 4,616 & $4,10^{\circ}$ & $11,23^{*}$ \\
\hline & B8 & 1,108 & 4,833 & $4,360^{\circ}$ & $11,03^{*}$ \\
\hline
\end{tabular}

* Diferente estatisticamente do Controle.

apenas os grupos A8 e B4 atuaram na redução significativa, contrariamente a A4 e B8, que aumentaram os mesmos (Figura 6).

Todas as médias referentes a peso úmido, diâmetro, diâmetro/peso e diâmetro corrigido estão descritas da Tabela 1. Nota-se que os tratamentos foram eficientes para impulsionar o desenvolvimento vegetativo das colônias, visto que todas cresceram de uma forma mais abundante do que os controles, conforme observado no peso úmido e diâmetro corrigido. As médias do diâmetro da colônia não foram, em nenhum tratamento e linhagem, significativamente diferentes.

\section{DISCUSSÃO}

Os dados obtidos através da germinação demostraram diferenças significativas, dos grupos tratados com as plantas de Aloe em relação aos controles, em todas as linhagens empregadas, porém, de maneira aleatória nos períodos de ocorrência.

Em todas as linhagens houve aceleração no processo de germinação, principalmente na biA1methG1 e CLB3, em que todos os tratamentos foram significativamente diferentes dos controles.
De acordo com D'Enfert (1997) cada fase do desenvolvimento da germinação é marcada por um conjunto de eventos morfogenéticos que refletem tanto o grupo de genes que se expressam quanto o tipo de influência que o ambiente pode exercer nesse momento. A fase de embebição coincide com a ativação do metabolismo do esporo, com sínteses, aumento dos níveis de ATP e elevação da taxa respiratória. A fase de brotamento do botão germinativo marca a primeira mitose do núcleo original do conídio e o eixo que se estabelece neste momento, é o eixo gerenciador para o crescimento polarizado da fase seguinte, que é de tubo germinativo. Diante disso, pode-se inferir que as espécies vegetais testadas neste estudo auxiliaram na ativação desses processos, o que explica os resultados positivos na aceleração da velocidade de germinação.

$\mathrm{Na}$ linhagem MSE, todos os tratamentos, exceto $A 4$, reduziram expressivamente o número de conídios mortos, quando comparado com o Controle, contrariamente do que ocorreu na linhagem biA1meth G1, em que nenhum tratamento foi significativo e da CLB3 em que apenas os tratamentos A8 e B4 foram eficazes.

Entretanto, o elevado percentual de esporos 
mortos observado em A4 e B8, na linhagem CLB3, pode estar relacionado à indução do mecanismo de apoptose na presença de conídios com danos genéticos. Assim como o observado por Tomasin \& Gomes-Marcondes (2011), em que o uso de $A$. barbadensis juntamente com o mel aumentou a apoptose de células tumorais em ratos, do mesmo modo que Di Luccia et al. (2013) confirmaram o efeito antiproliferativo em diversos tipos de células tumorais humanas de extratos da folha de $A$. arborescens.

Em relação à proteção de lesões no tubo germinativo (malformações), apenas na linhagem CLB3 todos os tratamentos se destacaram semelhantemente ao observado na linhagem biA1meth 1 , exceto pelo grupo A4. No entanto, resultados divergentes foram descobertos na linhagem MSE, pois apenas os grupos A8 e B4 beneficiaram de maneira expressiva a redução da taxa de malformados. Esses dados demonstram a eficácia das folhas da babosa na proteção durante o processo da germinação, apesar da grande variabilidade de respostas entre as linhagens, em concentrações idênticas, empregados nos testes de germinação. Pode-se inferir ainda, que a diminuição de malformados observada nos grupos tratados também pode indicar proteção antimutagênica, o que vem corroborar resultados encontrados de antimutagenicidade dessas mucilagens em diversos sistemas-teste, conforme Sturbelle et al. (2010) e Lissoni et al. (2009).

Com base nos dados de peso úmido e diâmetro corrigido verifica-se que os tratamentos estimularam o desenvolvimento vegetativo das colônias, uma vez que apresentaram nítido avanço nos grupos tratados com os géis vegetais, demonstrando que os mesmos potencializaram o desenvolvimento vegetativo de $A$. nidulans.

Apesar dos dados variarem em praticamente todos os experimentos deste trabalho, pode-se observar que ambas espécies de plantas foram eficazes no desenvolvimento do organismo, mesmo variando as concentrações.

Os resultados acima descritos indicam que as espécies de Aloe avaliadas se mostraram eficientes na homeostase do organismo $A$. nidulans, protegendo e beneficiando o seu desenvolvimento nas linhagens normais e na mutante CLB3, tendo em vista que a mesma é mutante para crescimento, esporulação e ciclo sexual. Pode-se deduzir que os tratamentos afetaram a expressão gênica, visto que tanto a velocidade de crescimento foi mais eficiente nos tratamentos do que no controle, bem como a redução significativa de malformados, diminuindo assim a taxa basal de mutações, característica dessa linhagem.

Dessa forma, a eficiência observada nos tratamentos com $A$. arborescens e $A$. barbadensis pode ser explicada pelas suas propriedades antioxidantes já comprovadas, tal como descrito por Beppu et al.(2003) e Di Luccia et al. (2013) referente à $A$. arborescens e Yu et al. (2009) e Toliopoulos et al. (2012) referente à $A$. barbadensis, pela capacidade de colaborar para a homeostase dos organismos, atividades antioxidantes e estímulos de autoproteção e autopreservação.

$\mathrm{O}$ excesso de radicais livres resulta em um estresse oxidativo no ambiente intra e extracelular e implicam na etiologia e progressão de muitas patologias. Uma lesão da membrana, por sua vez, expõe mais estruturas intracelulares, deixando vulnerável inclusive o DNA, podendo gerar mutações genéticas que desfavorecem a regulação do ciclo celular (Gomes, 2007; Hosseinimehr, 2007). Dessa forma, o mecanismo mais eficaz na restrição da ação de radicais livres é produzido pelos antioxidantes, tendo em vista que reagem e os eliminam antes de infringirem danos oxidativos em componentes vitais, tal como, DNA ou as membranas celulares (Halliwell et al., 1995; Mccord, 2000; Ratnam et al., 2006).

Tais fenômenos biológicos podem ser explicados também pela existência dos polissacarídeos acemanan e glicoman, presentes em ambas as espécies de Aloe, que atuam como imunomoduladores (Pecere et al., 2000; Lissoni et al., 2009). Ainda, segundo Imanishi (1993), a glicoproteína Aloctin A, substância extraída de $A$. arborescens, possui várias atividades biológicas e farmacológicas.

Os resultados positivos na homeostase dos organismos advindos do uso de $A$. barbadensis são em virtude da sua composição química, que é representada por vitaminas $\mathrm{A}, \mathrm{C}$ e $\mathrm{E}$, conhecidas por seu potencial antioxidante; enzimas variadas como peroxidase, catalase, alcalina fosfatase e amilase, que colaboram na redução de inflamações; minerais, como cálcio, cromo, selênio, magnésio, manganês, potássio, sódio e zinco, essenciais para o funcionamento de vários sistemas enzimáticos em diferentes vias metabólicas, além de também possuírem atividade antioxidante; polissacarídeos glicomanan e manose, com ação anti-inflamatória; antraquinonas como aloína e emodina, que atuam como analgésicos, antibactericidas e antivirais; e hormônios como auxina e giberilina que ajudam na ação anti-inflamatória (Surjushe et al., 2008).

Vale destacar que as atividades promovidas pelas plantas Aloe são extremamente qualificadas não somente em virtude de algum componente isolado, mas também e, principalmente, devido ao sinergismo entre as inúmeras substâncias potentes presentes em cada planta (Davis, 1997).

Os efeitos de ambas as plantas de Aloe testadas na homeostase de organismos não se

Rev. Bras. PI. Med., Campinas, v.17, n.4, p.534-542, 2015. 
restringem somente à estudos relacionados ao homem, assim como observado no presente estudo, em que os resultados apontaram grandes benefícios ao desenvolvimento do fungo $A$. nidulans. Picchietti et al. (2013), investigaram a ação de componentes extraídos de $A$. arborescens em linhagens de células de peixes, encontrando ações antibióticas e antimicrobianas, devido sua influência positiva ao sistema imunológico. Além disso, relatos associados à $A$. barbadensis demonstram ação antioxidante e aumento da atividade imunológica em ratos com úlceras (Yu et al., 2009) e efeitos antidiabéticos e antioxidantes em ratos com diabetes (Abo-Yousseef \& Messiha, 2013).

Os resultados obtidos neste estudo indicam o potencial benéfico dos tratamentos de $A$. arborescens e $A$. barbadensis no desenvolvimento vegetativo de linhagens normais e mutantes de $A$. nidulans. Dessa forma, justifica-se a importância na continuidade da investigação, visando contribuir para o esclarecimento dos mecanismos genéticos nos processos de promoção da homeostase, visto que em todos os organismos está relacionado direta ou indiretamente à saúde.

\section{REFERÊNCIAS}

ABO-YOUSSEF, A.M.H.; MESSIHA, B.A.S. Beneficial effects of Aloe vera in treatment of diabetes: Comparative in vivo and in vitro studies. Bulletin of Faculty of Pharmacy, Cairo University, v.51, n.1, p.7-11, 2013.

AFMAN, L.; MÜLLER, M. Nutrigenomics: From Molecular Nutrition to Prevention of Disease. Journal of American Dietetic Association, v.106, p.569-576, 2006.

BARACHO, M.S.; BARACHO, I.R. An analysis of the spontaneous mutation rate measurement in filamentous fungi. GENETICS and Molecular Biology, v.26, n.1, p.83-87, 2003.

BEPPU, $\mathrm{H}$. et al. Radical-scavenging effects of Aloe arborescens Miller on prevention of pancreatic islet B-cell destruction in rats. Journal of Ethnopharmacology, v.89, p.37-45, 2003.

CLUTTERBUCK, A.J. Aspergillus nidulans. In:KING, R.C.Handbook of Genetics. New York: Plenum Publishing, 1974. Cap.26, p.447-510.

D'ENFERT, C. Fungal spore germination: insights from the molecular genetics of Aspergillus nidulans and Neurospora crassa. Fungal Genetics and Biology, v.21, p.163-172, 1997.

DAVIS, R.H. Aloe Vera: A Scientific Approach. New York: Vantage Press Incorporated, 1997. 321p.

DI LUCCIA, B. et al. A Biochemical and Cellular Approach to Explore the Antiproliferative and Prodifferentiative Activity of Aloe arborescens Leaf Extract. Phytotherapy Research, v.27, n.12, p.1819-1828, 2013.

FERGUSON, L.R. et al. Dietary cancer and prevention using antimutagens.Toxicology, v.198, p.147-159, 2004.

GOMES, F.S. Carotenóides: uma possível proteção contra o desenvolvimento do câncer. Revista de Nutrição, v.20, n.5, p. 537-548, 2007.

HALLIWELL, B. et al. The Characterization of Antioxidants. Food Chemical and Toxicology, v. 33, n.7, p.601-617, 1995.

HOSSEINIMEHR, S.J. Foundation review: Trends in the development of radioprotective agents. Drug Discovery Today, v.12, n.19-20, p.794-805, 2007.

IMANISHI, K. Aloctin A, an Active Substance of Aloe arborescens Miller as immuno-modulator. Phytotherapy Research(Special Issue: Proceedings of the International Congress of Phytotherapy), v.7,n.7,p.20-22,1993.

LISSONI, P. et al. A Randomized Study of Chemotherapy Versus Biochemotherapy with Chemotherapy plus Aloe arborescensin Patients with Metastatic Cancer. in vivo, v.23, p.171-176, 2009.

MCCORD, J.M. The Evolution of Free Radicals and Oxidative Stress. The American Journal of Medicine, v.108, p.652-659, 2000.

MISAWA, E. et al. Administration of phytosterols isolated from Aloe vera gel reduce visceral fat mass and improve hyperglycemia in Zucker diabetic fatty (ZDF) rats. Obesity Research and Clinical Practice, v.2, p.239-245, 2008.

OJHA, S., et al. Aloe vera gel: A potent nutraceutical. Journal of Natural Pharmaceuticals, v.21, p.36-41, 2011.

O.M.S. - Organização Mundial de Saúde. $56^{\mathrm{a}}$ ASAMBLEA MUNDIAL DE LA SALUD: Punto 14.10 del orden del día provisional. Genebra: OMS, 2003.

PECERE, T. et al. Aloe-emodin is a new type of anticancer agent with selective activity against neuroectodermal tumors. Cancer Research, v.60, p. 2800-2804, 2000.

PICCHIETTI, S. et al. Immune modulatory effects of Aloe arborescens extract on the piscine SAF-1 cell line. Fish and Shellfish Immunology, v.34, n.5, p.1335-44, 2013.

PONTECORVO, G. et al. The genetics of Aspergillus nidulans. Advances in Genetics, v.5, p.141-238, 1953.

RAJASEKARAN, S. et al. Hypoglycemic Effect of Aloe vera Gel on Streptozotocin-Induced Diabetes in Experimental Rats. Journal of Medicinal Food, v.7, n.1, p.61-66, 2004.

RATNAM, D.V. et al. Role of antioxidants in prophylaxis and therapy: A pharmaceutical perspective. Journal of Controlled Release, v.113, p.189-207, 2006.

ROCHA, C. L. M. S. C.. Caracterização citológica, genética e Molecular de um mutante para a conidiogênese em Aspergillus nidulans. 1997. 203p. Tese (Doutorado em Agronomia) - Universidade de São Paulo, Piracicaba.

SANHUEZA, J.C.; VALENZUELA A. B. Nutrigenomics: revealing molecular aspects of a personalized nutrition. Revista Chilena de Nutrición, v.39, n.1, p.71-85, 2012.

SINGH, R.P et al. Chemomodulatory action of Aloe vera on the profiles of enzymes associated with carcinogen metabolism and antioxidant status regulation in mice. Phytomedicine, v.7, n.3, p.209-19, 2000.

SOUSA, G.D. et al. Aspergillus nidulans as a biological system to detect the genotoxic effects of mercury fumes on eukaryotes. Genetics and Molecular Research, v.8, n.2, p.404-413, 2009.

STURBELLE, R.T. et al. Avaliação da atividade mutagênica e antimutagênica da Aloe vera em teste de Allium

Rev. Bras. PI. Med., Campinas, v.17, n.4, p.534-542, 2015. 
cepa e teste de micronúcleo em linfócitos humanos binucleados. Revista Brasileira Farmacognosia, v.20, n.3, p.409-415, 2010.

SURJUSHE, A. et al. Aloe vera: A short review. Indian Journal of Dermatology, v. 53, n.4, p.163-166, 2008.

TOLIOPOULOS, I. et al. NK cell stimulation by administration of vitamin $\mathrm{C}$ and Aloe vera juice in vitro and in vivo: A pilot study. Journal of Herbal Medicine, v.2, p.29-33, 2012

TOMASIN, R.; GOMES-MARCONDES, M.C.C.G. Oral administration of Aloe vera and honey reduces walker tumour growth by decreasing cell proliferation and increasing apoptosis in tumour tissue. Phytotherapy Research, v.25, n.4, p.619-623, 2011.

W.H.O. -World Health Organization. Tradicional Medicine Strategy 2002-2005. Geneve: WHO, 2002. 65p.

WICHTL, M. Herbal Drugs and Phytotopharmaceuticals. Stutgard: Medpharma Scientific Publishers, v.704, p.25-29. 2004

YU, Z. et al. Effect of Aloe vera polysaccharides on immunity and antioxidant activities in oral ulcer animal models. Carbohydrate Polymers, v.25, p.307-311, 2009. 